\title{
Numerical investigation of fuel temperature effects on the cavitation within a single-hole diesel nozzle
}

\author{
Yun Wang, Jianwen Wang \\ Department of mechanical and power engineering, East China University of Science and \\ Technology, Shanghai, 200237, China
}

Keywords: Homogeneous Equilibrium Model, Temperature effects, Cavitation, Diesel nozzle

\begin{abstract}
Based on Homogeneous Equilibrium Model combined with full cavitation model, the cavitation flow inside a single-hole diesel nozzle is simulated. In order to analyse the effect of the fuel temperature increase on the characteristics of the internal cavitating flow, the inception and development of cavitation inside the diesel nozzle were analysed separately. Furthermore, the effect on the outlet velocity was also discussed. The computational results show that the temperature rising had significant effects on the cavitation flow inside a diesel nozzle. With the rising of fuel temperature, the cavitation phenomenon inside the nozzle appeared earlier, the transition to supercavitation was accelerated and the outlet velocity increased.
\end{abstract}

\section{Introduction}

Cavitation has been known to appear inside diesel nozzles for a long time. Even though the collapse of cavitation bubbles can lead to the surface erosion, cavitation inside the nozzle is expected to enhance fuel atomization, thus improving the combustion and reducing emissions in Diesel engines. Through experiments on real-sized or large-scaled nozzle, researchers have gained basic knowledge of this phenomenon [1-3]. On the other hand, numerical simulation has been proved to be another useful method to study cavitation [4, 5].

However, most previous studies, whether through experiment or numerical simulation, have been based on the assumption that fuel temperature inside the nozzle is constant. In actual diesel engine, fuel temperature can vary from below $0^{\circ} \mathrm{C}$ at cold start engine conditions to $150^{\circ} \mathrm{C}$, or even higher [6]. Thus, the effect of fuel temperature variations cannot be ignored readily. Nevertheless, few researches have focused on investigating such effects. Following the results of He [7], it turns out that cavitation inception was accelerated by the rising of the fuel temperature, comparing cavitation with the fuel temperature of $17^{\circ} \mathrm{C}$ and $77^{\circ} \mathrm{C}$. Apparently, the result is not convincing enough since the experiment carried out under only two temperature values. M. G. De Giorgi et al. [8] found that the length and behaviour of the cavitation were affected by liquid temperature by experimentally investigating a two-phase flow of water flow in a sharp-edged orifice. In fact, using water as the working fluid does not reflect the properties of fuel. Hence, it is still necessary to investigate the effect of fuel temperature taking into account realistic operating conditions in order to better understand and control cavitation in the future.

Considering the actual temperature effects on cavitation flow is extremely complicated, it is difficult to directly build a feasible cavitation model coupled with the temperature variations. However, based on the experimental results of P. G. Aleiferis [9], the physical properties of fuel (density, viscosity and vapor pressure etc.) will vary with the change of fuel temperature. Obviously, there should be a group of unique values of fuel properties for every single temperature, which means that it is proper to use the change of fuel properties to simulate temperature variations. The objective of the present study is to provide more insight to the details of the effect of fuel temperature on cavitation. Thus, a CFD calculation of a diesel nozzle by using Fluent 6.3 is performed in this study. Data of fuel properties at various temperatures derived from experiments [10] are used to simulate actual effects of temperature (ranges from $30^{\circ} \mathrm{C}$ to $150^{\circ} \mathrm{C}$ ). To be more specific, the effect of fuel temperature on the inception and development of the cavitation inside the 
nozzle are separately investigated in detail. Furthermore, the influence of fuel temperature on the outlet velocity is also discussed.

\section{Mathematical models and parameters}

In present study, Homogeneous Equilibrium Model combined with full cavitation model used in previous studies $[4,5]$ is adopted to simulate the cavitating flow. In order to describe the cavitation characteristics in nozzles, two important non-dimensional parameters are introduced, which are the discharge coefficient and the cavitation number. The discharge coefficient $C_{d}$ is defined as the ratio of actual flow rate and theoretical one, which usually used as description of flow efficiency within nozzles.

$$
C_{d}=\frac{q_{m}}{A \sqrt{2 \rho\left(p_{1}-p_{2}\right)}}
$$

Where $q_{\mathrm{m}}$ is actual flow rate, $A$ is cross-section area of a nozzle hole, $p_{1}$ is injection pressure and $\mathrm{p}_{2}$ the backpressure. Cavitation number can be written as follow:

$$
K=\frac{p_{1}-p_{v}}{p_{1}-p_{2}}
$$

Where $p_{\mathrm{v}}$ is the saturated vapor pressure.

\section{Numerical simulations description}

A single-hole diesel nozzle is used for numerical simulation in this study, whose geometrical features are shown in Fig.1. The radius of the chamber $R$ is $0.65 \mathrm{~mm}$, the diameter of the nozzle hole $D$ is $0.26 \mathrm{~mm}$, and the ratio of the length and diameter $L / D$ is 2.5 . In our case, a two-dimension diesel nozzle model is adopted in numerical simulation for simplicity in solving. Thus, computational domain and grids for the nozzle can be observed in Fig.2.

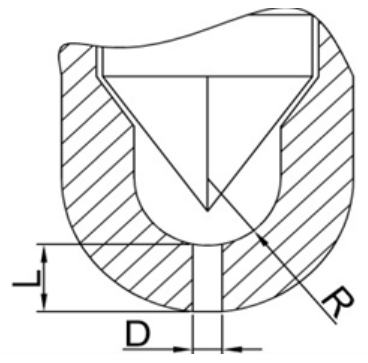

Fig.1: Structure of a single-hole diesel nozzle

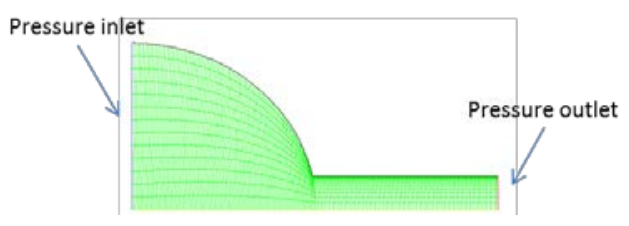

Fig.2: Computational domain and grids

To simulate realistic conditions inside diesel nozzle, 0\#diesel fuel is used as the working fluid, whose fuel properties against temperature variations are listed in Table 1.

Table 1: Diesel properties variation with the change of temperature

\begin{tabular}{ccccc}
\hline $\begin{array}{c}\text { Temperature } \\
\left({ }^{\circ} \mathrm{C}\right)\end{array}$ & $\begin{array}{c}\text { Vapor pressure } \\
(\mathrm{Pa})\end{array}$ & $\begin{array}{c}\text { Viscosity } \\
(\mathrm{Pa} \cdot \mathrm{S})\end{array}$ & $\begin{array}{c}\text { Density } \\
\left(\mathrm{Kg} / \mathrm{m}^{3}\right)\end{array}$ & $\begin{array}{c}\text { Surface tension } \\
(\mathrm{N} / \mathrm{m})\end{array}$ \\
\hline 30 & 120 & 0.00341 & 818 & 0.02726 \\
60 & 493 & 0.00182 & 800 & 0.02482 \\
70 & 560 & 0.00151 & 795 & 0.02410 \\
80 & 1175 & 0.00123 & 785 & 0.02312 \\
90 & 2020 & 0.00113 & 780 & 0.02245 \\
120 & 4939 & 0.00083 & 762 & 0.01978 \\
150 & 9466 & 0.00054 & 744 & 0.01734 \\
\hline
\end{tabular}




\section{Results and discussions}

\section{Influence on the cavitation inception}

Fig.3 displays the discharge coefficient and mass flow versus the injection pressure. Results for the fuel temperature of $30^{\circ} \mathrm{C}, 90^{\circ} \mathrm{C}, 120^{\circ} \mathrm{C}$, and $150^{\circ} \mathrm{C}$ are depicted separately. Note that a similar trend for all temperatures can be observed: the discharge coefficient increases linearly with the injection pressure until a point where it stabilizes; the discharge coefficient then collapses, which can be used as a non-intrusive way to detect cavitation [5]. In addition, pressure conditions needed to reach this situation are called critical cavitation condition. The critical cavitation conditions are graphed in Fig.4: the critical injection pressure needed to induce cavitation is provided for each temperature. The lower the critical injection pressure needed, the more prone the nozzle is to activate.

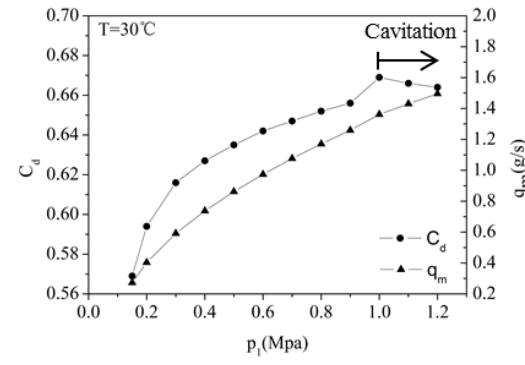

(a)

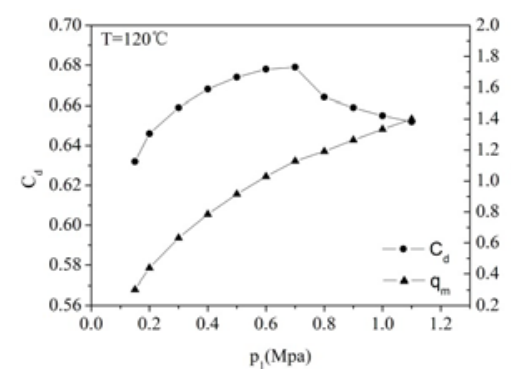

(c)

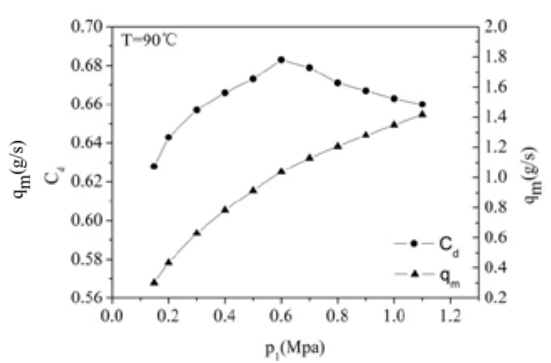

(b)

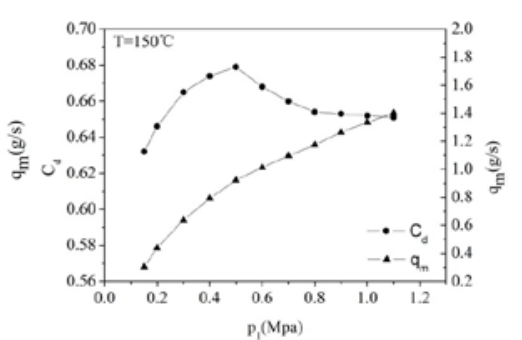

(d)

Fig.3: Discharge coefficient $C_{d}$ and mass flow $\mathrm{q}_{\mathrm{m}}$ vs fuel temperature

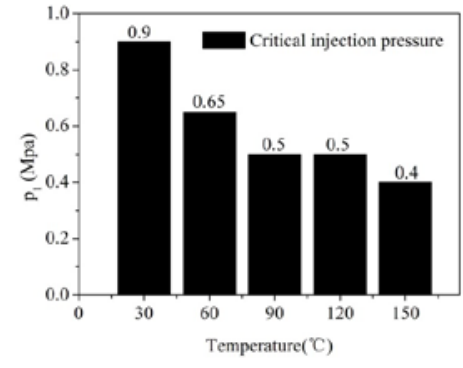

(a)

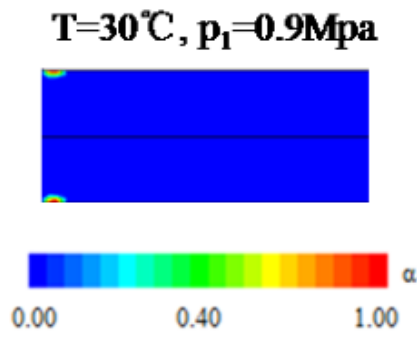

(b)

Fig.4: Critical injection pressure vs fuel temperature

Fig.4 clearly displays the change of injection pressure for incipient cavitation in consideration of temperature. Clear cavitation bubble clouds appear near the inlet of the nozzle when fuel temperature is $30^{\circ} \mathrm{C}$. At $60^{\circ} \mathrm{C}$, the cavitation inception takes place when injection pressure reaches to $0.65 \mathrm{Mpa}$. Furthermore, the critical injection pressure drops to only $0.45 \mathrm{Mpa}$ when fuel temperature goes to $150{ }^{\circ} \mathrm{C}$. As the fuel temperature increases, the critical injection pressure is decreasing. In the range $30 \sim 150^{\circ} \mathrm{C}$, the injection pressure decreases by $50 \%$. Likewise, the value of cavitation number $K$ related to the critical cavitation conditions is named as the critical cavitation number, $K_{\text {crit }}$. Cavitation inception occurs until $K_{\text {crit }}$ is reached. The values of $K_{\text {crit }}$ with the temperature range varied between $30^{\circ} \mathrm{C}$ and $150^{\circ} \mathrm{C}$ are given in Table 2 . As expected, the values present a trend of rising. A higher value of $K_{\text {crit }}$ means that the flow has a greater aptitude to cavitate. 
Table 2: Critical cavitation number at different temperatures

\begin{tabular}{ccccccc}
\hline Temperature $\left({ }^{\circ} \mathrm{C}\right)$ & 30 & 60 & 90 & 120 & 140 & 150 \\
\hline$K_{\text {crit }}$ & 1.12 & 1.18 & 1.24 & 1.24 & 1.27 & 1.30 \\
\hline
\end{tabular}

\section{Influence on the cavitation development}

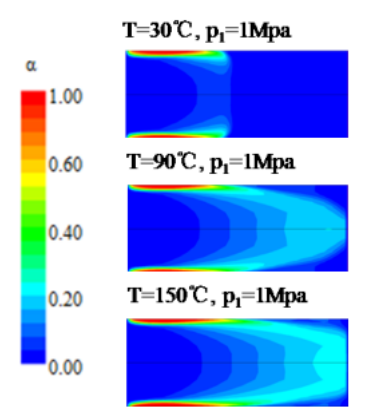

(a)

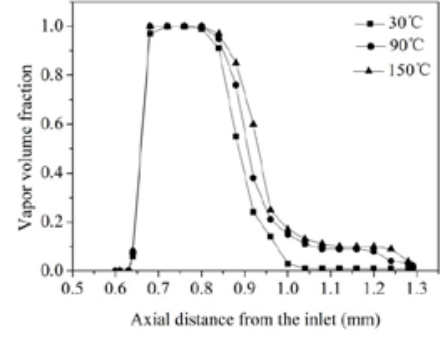

(b)

Fig.5: Effect of fuel temperature on distributions of cavitation

With the injection pressure increase, the flow pattern moves to the developed cavitation regime after the cavitation inception. If the pressure further increases, supercavitation will finally be reached. In order to investigate the impact of fuel temperature on these two patterns, cavitating flows at different temperature $\left(30^{\circ} \mathrm{C}, 90^{\circ} \mathrm{C}\right.$, and $150^{\circ} \mathrm{C}$ ) were separately simulated. Simulations are conducted with $1 \mathrm{Mpa}$ injection pressure and 0.1Mpa backpressure. Fig.5 (a) shows changes in cavitation clouds with the rising of fuel temperature. The cavitation zone is clearly longer at $90^{\circ} \mathrm{C}$ than at $30^{\circ} \mathrm{C}$. In addition, temperature -dependence distribution curves of vapor volume fraction plotted in Fig.5 (b) show a clear discrepancy on the cavitation growth with temperature changes. Note that the curves present trends of "upwards" and "rightwards" when fuel temperature was raised from $30^{\circ} \mathrm{C}$ to $150^{\circ} \mathrm{C}$, which indicates that the cavitation zone becomes "thicker" and "longer". For further analysis, cavitating flow at other two injection pressures (8Mpa, 15Mpa) were simulated, whose results are shown in Fig.6. It turns out that the influence of fuel temperature on cavitation growth is still remarkable despite of a rapid change in injection pressure. Therefore, these simulation results prove that the cavitation inside the nozzle was enhanced due to the increase in fuel temperature. Additionally, another interesting discovery is that the discrepancy decreased gradually with the injection pressure increase by comparing the shape of distribution curves at 8Mpa and 15Mpa. As can be observed in Fig.6 (b), when supercavitation appeared (with an injection pressure of $15 \mathrm{Mpa}$, cavitation clouds have extended to the exit of the nozzle), the influence of fuel temperature was relatively small since the curves at different temperatures nearly overlapped.

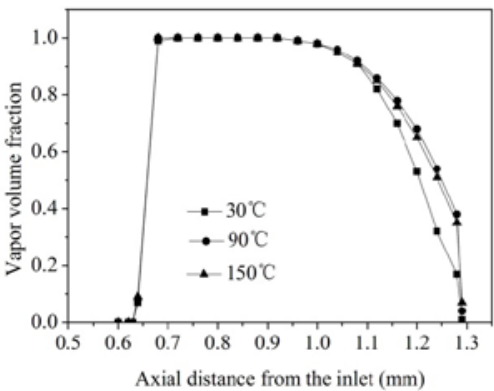

(a) $\mathrm{p} 1=8 \mathrm{Mpa}$

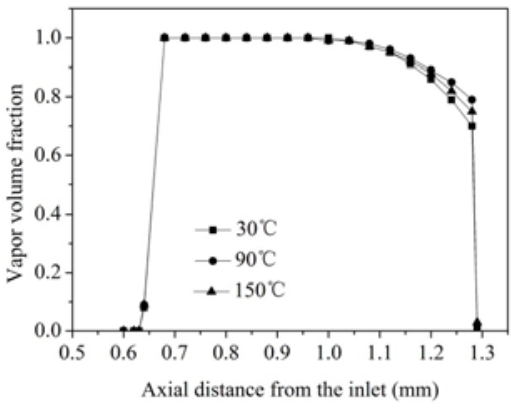

(b) $\mathrm{p} 1=15 \mathrm{Mpa}$

Fig.6: Cavitation distributions under p1= 8Mpa, 15Mpa 


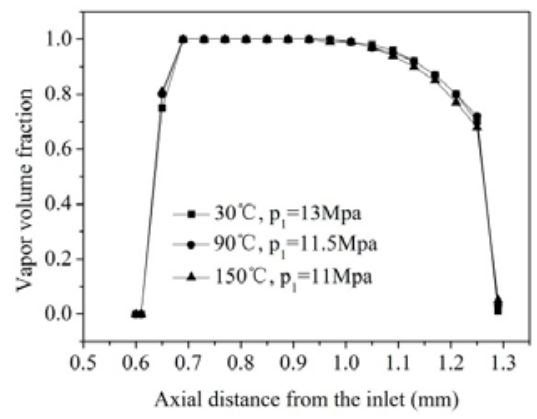

Fig.7: Injection pressure for supercavitation at different temperatures

Meanwhile, in order to better understand the influence of fuel temperature on supercavitation, more detailed simulations were carried out, which turns out that supercavitation appeared at lower injection pressure while fuel temperature increased. In Fig.7, the injection pressure for supercavitation decreases when temperature increases: it is $13 \mathrm{Mpa}$ at $30^{\circ} \mathrm{C}$ but $11 \mathrm{Mpa}$ at $150^{\circ} \mathrm{C}$. Thus, a conclusion can be drawn that temperature affected the growth of cavitation and also accelerated the transition to a supercavitation regime. It may be contributed to that cavitation bubbles are more prone to form due to a radical rising of vapor pressure induced by the fuel temperature increase. Moreover, higher temperature is in favour of a rapid growth of cavitation bubbles.

\section{Influence on the outlet velocity}

It is well know that the outlet velocity has significant effects on the fuel spray [11]. Thus, it is necessary to investigate the influence of the fuel temperature on the outlet velocity.

As shown in Fig.8, the curves of the outlet velocity are given under the injection pressure of $1 \mathrm{Mpa}$ and the fuel temperature of $30^{\circ} \mathrm{C}, 90^{\circ} \mathrm{C}$ and $150^{\circ} \mathrm{C}$, respectively. It turns out that the outlet velocity profile is reorganized with the temperature increase: as the fuel temperature increases, the profile of the outlet velocity becomes more "flat", and the velocity at the vicinity of the nozzle wall increases remarkably. This is mainly because that the cavitation leads to a reduction of effective cross-section in the nozzle, thus resulting in increased flow velocity; since higher fuel temperature can enhance the cavitation as analysed above, the outlet velocity will increase with the rising of temperature. Additionally, higher fuel temperature will cause a reduction of fuel viscosity in the cavitation zone along the nozzle wall, which in turn decreases the friction losses in the nozzle, then largely increasing the velocity near the nozzle wall. On the other hand, higher outlet velocity means that fuel jet will be more prone to form tiny droplets, therefore producing better atomization and then improving fuel/air mixing process.

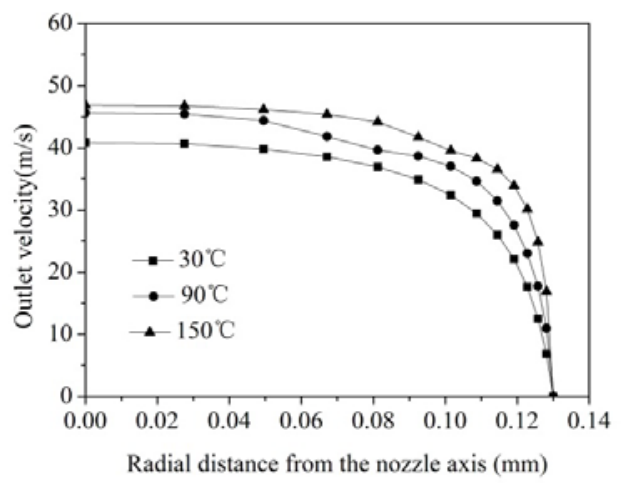

Fig.8: Outlet velocity at different fuel temperatures

\section{Conclusion}

1. Fuel temperature has effects on the cavitation inception. With the fuel temperature increase, the critical injection pressure decreases while critical cavitation number increases, which indicates 
that the ability to resist cavitation weakened. In other words, cavitation is more prone to appear at high fuel temperatures.

2. The effect of fuel temperature on the process of cavitation development is also remarkable. By increasing fuel temperature, cavitation clouds inside nozzle extends, which indicates that the cavitation zone became "thicker" and "longer". Meanwhile, higher fuel temperature accelerates the transition process from developed cavitation to supercavitation. Additionally, once supercavitation appears, the effect of fuel temperature becomes insignificant.

3. Outlet velocity is also influenced by the rising of fuel temperature, which presents a trend of rising. It can be attributed to the reduction in fuel viscosity and improved flow properties inside nozzle.

\section{References}

[1] Badock, C., Wirth, R., Fath, A. \& Leipertz, A., Investigation of cavitation in real size diesel injection nozzles. International Journal of Heat and Fluid Flow, 20(5), pp.538-544, 1999.

[2] Payri, R., Salvador, F.J., Gimeno, J. \& De la Morena, J., Study of cavitation phenomena based on a technique for visualizing bubbles in a liquid pressurized chamber. International Journal of Heat and Fluid Flow, 30(4), pp.768-777, 2009.

[3] Payri, R., Garcia, J.M., Salvador, F.J. \& Gimeno, J., Using spray momentum flux measurements to understand the influence of diesel nozzle geometry on spray characteristics. Fuel, 84, pp.551-561, 2005.

[4] Habchi, C., Dumont, N. \& Simonin, O., Multidimensional simulation of cavitating flows in diesel injectors by a homogeneous mixture modeling approach. Atomization Sprays, 18(2), pp.129162, 2008

[5] Singhal, A.K., Athavale, M. M., Li, H. \& Jiang, Y., Mathematical basis and validation of the full cavitation model. Journal of fluids engineering, 124(3), pp.617-624.2002.

[6] Aleiferis, P.G., Serras-Pereira, J., Augoye, A., Davies, T. J., Cracknell, R.F. \& Richardson, D, Effect of fuel temperature on in-nozzle cavitation and spray formation of liquid hydrocarbons and alcohols from a real-size optical injector for direct-injection spark-ignition engines. International Journal of Heat and Mass Transfer, 53(21), pp.4588-4606, 2010.

[7] Zhi Xia-He, Wen Jun-Zhong, Qian Wang, Zhao Chen-Jiang \& Ya Nan-Fu, An investigation of transient nature of the cavitating flow in injector nozzles. Applied Thermal Engineering, 54(1), pp.56-64, 2013.

[8] De Giorgi, M.G., Ficarella, A. \& Tarantino, M., Evaluating cavitation regimes in an internal orifice at different temperatures using frequency analysis and visualization. International Journal of Heat and Fluid Flow, 39, pp.160-172, 2013.

[9] Aleiferis P.G. \&Van Romunde Z.R., An analysis of spray development with iso-octane, npentane, gasoline, ethanol and n-butanol from a multi-hole injector under hot fuel conditions. Fuel, 105, pp.143-168, 2013

[10] Yoon, S.H., Park, S.H. \& Lee, C.S., Experimental Investigation on the Fuel Properties of Biodiesel and its Blends at Various Temperatures. Energy \& Fuels, 22(1), pp.652-656, 2008.

[11] Huh, K.Y, Lee, E. \& Koo, J., Diesel spray atomization model considering nozzle exit turbulence conditions. Atomization and Sprays, 8(4), pp.453-469, 1998. 